\title{
O controle de acesso na percepção dos profissionais de arquivo: uma questão de segurança das informações institucionais
}

\section{Josiane Ayres Sfreddo}

\author{
Graduanda do Curso de Arquivologia da UFSM
}

Daniel Flores

\section{Professor Adjunto do Departamento de Documentação da UFSM}

Apresenta-se o resultado de uma investigação científica baseada nas políticas utilizadas nas instituições arquivísticas para o controle de acesso, destacando-se a importância de monitorar o acesso aos documentos, evitando problemas futuros. A referência teórica do trabalho baseou-se nas Normalizações Arquivísticas $\operatorname{ISAD}(\mathrm{G})$, ISO 15489, Nobrade, e nos Modelos de Requisitos MoReq e e-ARQ. Os dados foram coletados no Arquivo Público do Estado do Rio Grande do Sul e no Arquivo Histórico de Porto Alegre Moysés Vellinho, ambos em Porto Alegre, RS.

Palavras-chave: Controle de acesso; Segurança informacional; Normalizações arquivísticas; Modelos de requisitos.

\section{The access control in the perception of archivist professionals: a matter of security from institutional information.}

This article presents the result of a scientific investigation based on the rules used in archivist institutions for the control access, avoiding future problems. The theoretical reference of this work based on the archivist norms $\operatorname{ISAD}(\mathrm{G})$, ISO 15489, Nobrade and of the models requirements MoReq and e-ARQ. The data were collected at the Public Archives of Rio Grande do Sul State and at the Historical Archives of Porto Alegre Moysés Vellinho, both in Porto Alegre, RS. 
Keywords: Access control; Informational security; Archivist norms; Models requirements.

Recebido em 03.09.2008 Aceito em 24.07.2009

\section{Introdução}

Os processos de gestão documental, nas instituições arquivísticas, devem poder monitorar o controle de acesso aos documentos, realizando ações que garantam a segurança e a integridade das informações no futuro.

O acesso documental é um direito do cidadão e cabe ao profissional arquivista disponibilizá-lo, por meio do desenvolvimento de instrumentos de pesquisa e da adoção de políticas de gestão, visando à facilidade, garantia e continuidade do acesso aos documentos.

O acesso dos usuários aos documentos, em uma instituição, deve basear-se em teorias ou nas práticas anteriormente aplicadas, seguindo um padrão ou regras mínimas para controlar as ações referentes a ele. As Normalizações Arquivísticas contribuem para a materialização dos instrumentos de pesquisa, facilitando sobremaneira o acesso dos usuários aos documentos.

Assim, o uso e controle dos procedimentos informáticos em uma instituição, embora não correspondendo a um sistema de gerenciamento eletrônico, ou não estando diretamente relacionado aos instrumentos de pesquisa documental, deve ser planejado para atender às necessidades de acesso e preservação.

Portanto, ao analisar-se o acesso e as políticas de controle adotadas nas instituições, pode-se aprimorar e adequar os métodos utilizados no controle de acesso, garantindo, assim, maior segurança das informações institucionais.

Além de respeitar o código de ética que rege sua vida profissional, o arquivista deve ser crítico o suficiente para avaliar positiva ou negativamente suas ações. Pensando nisso, buscou-se saber quais as políticas de controle de acesso são adotadas no Arquivo Público do Estado do Rio Grande do Sul (APERS) e no Arquivo Histórico de Porto Alegre Moysés Vellinho (AHPAMV), assim como a opinião dos técnicos de arquivo a respeito da eficácia dessas políticas na segurança das informações. Para isso, o trabalho teve como eixo teórico as Normalizações Arquivísticas e os Modelos de Requisitos, como forma de regulamentar o controle de acesso de acordo com padrões pré-estabelecidos, realizando, assim, a identificação das políticas aplicadas na prática profissional.

\section{Controle de acesso}

Para implantar atividades de gestão documental é necessário contar com o apoio e o consentimento da instituição que irá sistematizá-las. 
Para facilitar o acesso, os profissionais arquivistas elaboram instrumentos de pesquisa para cooperar na gestão documental. Nessa perspectiva, Cardoso e Luz (2005) afirmam que ao se produzir e difundir as informações, sejam eletrônicas ou digitais, compete aos profissionais estar constantemente atualizados para empregar ações inovadoras no tratamento dos documentos. A fim de preservar a segurança dessas informações, as instituições adotam medidas para monitorar seu acervo. O controle do acesso pode ser feito por meio do cadastro dos usuários, pelo crachá de identificação, ou até mesmo pela restrição do espaço do acervo ao uso exclusivo dos funcionários.

Conforme 0 Instituto dos Arquivos Nacionais/Torre do Tombo (2002), o controle de acesso em instituições é feito por regras que determinam quem está autorizado ou não a acessar determinados conjuntos documentais e em que ocasião isto é consentido. No caso de documentos digitais e eletrônicos, deve-se verificar a segurança e a confiabilidade do software utilizado, além de manter cópias de segurança para evitar a perda de informação.

Quanto ao tratamento de documentos digitais, deve-se citar o Modelo OAIS (Open Archival Information System), pois ele dá diretivas para o acesso e a preservação digital a longo prazo. Saramago (2004, p. 5) assegura que "o modelo fornece uma estrutura útil de desenvolvimento de metadados para a preservação que vai ao encontro dos requisitos necessários a uma actividade de preservação digital".

A Câmara Técnica de Documentos Eletrônicos (2006, p. 32) afirma que a instituição "precisa limitar ou autorizar o acesso a documentos, por usuário e/ou grupos de usuários", garantindo, no mínimo, as funções de restrição de acesso, a exibição dos documentos somente aos usuários autorizados (no caso de sistemas informatizados) e o uso ou a intervenção nos documentos para usuários com autorização.

Concomitantemente ao controle de acesso, uma instituição pode adotar medidas como as trilhas de auditoria e as cópias de segurança. Em relação à última, o Instituto dos Arquivos Nacionais/Torre do Tombo (2002) recomenda que, para a segurança dos documentos, a instituição deve seguir medidas que protejam e previnam as possíveis falhas do sistema. Entre os procedimentos de salvaguarda estão as cópias de segurança, que têm por objetivo prevenir perdas e garantir a disponibilidade da informação, seja em sistemas informatizados de gestão ou não.

Os modelos de requisitos MoReq e e-ARQ, utilizados na adoção de políticas de controle de acesso, não se aplicam somente a sistemas informatizados de gestão documental, podendo ser seguidos tanto no tratamento de documentos convencionais quanto digitais.

Como exposto anteriormente, as organizações devem monitorar o acesso aos documentos de arquivo, além de restringi-los, seguindo a legislação vigente, regulamentos e normas internas estabelecidas pela própria instituição. 
Em consonância com o Instituto dos Arquivos Nacionais/Torre do Tombo (2002), para preservar estas informações são estabelecidas categorias de segurança que podem ser subdivididas hierarquicamente ou arranjadas de maneira distinta, conforme a necessidade e a especificidade de cada instituição.

Segundo o Fórum do Patrimônio Documental (2006, p. 8), "a instituição deve registrar cada consulta de forma correta e objetiva, e esses registros devem ser guardados em local seguro e por um longo prazo, para que possam estar disponíveis e rapidamente recuperáveis a qualquer instante". No caso de perdas ou furtos, a adoção desta medida possibilita a identificação do usuário que utilizou a documentação e de quando ocorreu sua consulta.

A atividade arquivística deve sempre considerar, entre outros aspectos, o grau de sigilo da documentação em questão, qualquer que seja seu suporte. No meio digital, os níveis de acesso determinam esse grau de sigilo, estando em consonância com a Legislação vigente (LUZ, 2008).

\subsection{Aspectos legais referente ao acesso}

No site do Conselho Nacional de Arquivos ${ }^{1}$ é possível ter conhecimento sobre a Legislação Arquivística Brasileira; todas as leis, decretos e demais regulamentos que se aplicam no exercício da profissão arquivística. No que se refere ao acesso documental, a legislação define:

1. A Constituição da República Federativa do Brasil, de 1988, assegura o acesso à informação, resguardando o sigilo da fonte, sendo que todos têm "o direito a receber dos órgãos públicos informações de seu interesse particular, ou de interesse coletivo ou geral, que serão prestadas no prazo da lei, sob pena de responsabilidade, ressalvadas aquelas cujo sigilo seja imprescindível à segurança da sociedade e do estado" (BRASIL, 1988);

2. A Lei n. 9.507, de 12 de novembro de 1997, regulamenta o direito de acesso a informações e disciplina o rito processual do habeas data. Os registros ou banco de dados serão de caráter público se contiverem informações utilizadas especificamente pela organização ou instituição que as produziu (BRASIL, 1997);

3. O Decreto No 3.505, de 13 de junho de 2000, publicado no Diário Oficial da União (DOU) de 14/06/2000, institui a Política de Segurança da Informação nos órgãos e entidades da Administração Pública Federal, garantindo 0 acesso aos sistemas de informação somente para usuários autorizados, para evitar modificação ou perda de informação (BRASIL, 2000);

\footnotetext{
${ }^{1}$ Disponível em: <http://www.conarq.arquivonacional.gov.br>. Acesso em: 11 ago. 2009.
} 
4. O Decreto No 4.553, de 27 de dezembro de 2002, determina a preservação de dados, informações, documentos e materiais sigilosos, sendo que os últimos possuem acesso restrito. "Os dados ou informações sigilosos serão classificados em ultrasecretos, secretos, confidenciais e reservados, em razão do seu teor ou dos seus elementos intrínsecos" (BRASIL, 2002);

5. A Resolução no 20, de 16 de julho de 2004, inclui os documentos digitais nos programas de gestão de documentos arquivísticos das instituições que fazem parte do Sistema Nacional de Arquivos. É dever do Poder Público tornar acessível aos cidadãos as informações contidas nos documentos de caráter governamental (BRASIL, 2004).

Ao analisar aspectos da Legislação Arquivística referentes ao direito de acesso, às restrições de uso e aos graus de sigilo documental, verificase que a instituição deve adotar, também, procedimentos padronizados que sistematizem os processos de produção, tramitação, uso e destinação dos documentos.

\subsection{Normalizações arquivísticas e modelos de requisitos}

As Normalizações Arquivísticas servem para sistematizar o gerenciamento de documentos, sejam eles eletrônicos ou não, através da adoção de medidas a serem seguidas em busca da padronização das atividades. Sendo assim, "a normalização não se refere simplesmente à descrição arquivística, pois ela envolve, também, todas as fases da gestão documental" (HEREDIA HERRERA, 2008, p. 13, tradução nossa).

Da mesma forma, os modelos de requisitos abordam conjuntos de procedimentos a serem aplicados em sistemas informatizados ou não informatizados de gestão documental.

Entre as Normalizações mais conhecidas no meio arquivístico está a General International Standard Archival Description - ISAD (G). Para Leão (2006), com a normalização $\operatorname{ISAD}(G)$ o acesso ao conteúdo dos documentos foi definido prioritário e fundamental para a descrição arquivística.

$\operatorname{A} \operatorname{ISAD}(G)$ foi a primeira normalização desenvolvida para a descrição arquivística aprovada no Brasil. Essa norma, apesar de fazer referência à documentação eletrônica, não apresenta campos específicos para tal tratamento. Norma esta que é muito bem aceita no Brasil, pois até o ano de 2006 não existia Normalização Brasileira.

A publicação da Norma Brasileira de Descrição Arquivística (Nobrade), baseada no modelo da $\operatorname{ISAD}(G)$, pode ser utilizada pela comunidade arquivística como norma padrão. Pois ela, segundo o Conselho Nacional de Arquivos (2006, p. 10), "estabelece diretivas para a descrição no Brasil de documentos arquivísticos, compatíveis com as normas internacionais em vigor ISAD(G) e ISAAR(CPF), e tem em vista facilitar o acesso e o intercâmbio de informações em âmbito nacional e 
internacional". Sua versão final foi recentemente publicada, tendendo a ser utilizada como padrão nacional de Descrição Arquivística, substituindo a $\operatorname{ISAD}(\mathrm{G})$, que é adotada atualmente como padrão.

A Norma Brasileira de Descrição deve ser difundida, tornando-se conhecida não somente pelos profissionais arquivistas, mas também pelos profissionais das áreas afins, possibilitando, dessa forma, o seu aperfeiçoamento. Sua descrição sobre o acesso assemelha-se muito à da $\operatorname{ISAD}(\mathrm{G})$, porém apresenta os tipos mais comuns de restrição de acesso e expõe de uma forma mais simplificada os procedimentos técnicos de descrição arquivística.

O emprego de um sistema de gestão leva tempo, requer dedicação e envolve uma série de procedimentos que, postos em prática, facilitam a busca à informação. A aplicação de um sistema de gestão de arquivos eletrônicos é mais complexa devido à falta de instrumentos que orientem sua aplicação.

O modelo MoReq surgiu da necessidade de uma especificação, com requisitos que fossem direcionados à gestão de arquivos eletrônicos, principalmente nos órgão públicos, onde a escassez de instrumentos eficazes é grande. Ela descreve um Modelo de Requisitos para a gestão de arquivos eletrônicos, destacando os requisitos funcionais através de um Sistema de Gestão de Arquivos Eletrônicos - SGAE (INSTITUTO DOS ARQUIVOS NACIONAIS/TORRE DO TOMBO, 2002).

A especificação MoReq destina-se a servir de ferramenta prática para auxiliar as organizações no exercício das atividades referentes à gestão de documentos de arquivos eletrônicos e não eletrônicos. O acesso aos documentos é abordado de forma a verificar a eficiência do software utilizado na instituição. O administrador, ou seja, o arquivista, é quem define o acesso por usuários ou grupos de usuários. Ele também deve verificar constantemente quem possui direito de acesso, quais os níveis de segurança e quais as restrições de acesso, estando sempre em consonância com a legislação vigente.

Seguindo a mesma linha prática do MoReq, o e-ARQ estabelece condições mínimas para a implantação de um Sistema Informatizado de Gestão Arquivística de Documentos Digitais $\mathrm{SIGAD}^{2}$, e, assim como o MoReq, utiliza também um software para sua aplicação. Levando-se em consideração o referencial teórico presente na e-ARQ, é possível admitir sua amplitude, significância e acessibilidade, ainda que sua versão final não tenha sido publicada. Para a adoção de políticas arquivísticas, uma instituição deve ter um embasamento teórico amplo, reconhecer suas atividades, os documentos que produz e o contexto em que eles são criados.

As medidas adotadas para segurança documental, de acordo com os pressupostos do e-ARQ, visam à identificação do usuário. Segundo a Câmara Técnica de Documentos Eletrônicos (2006), o acesso deve ser somente a usuários autorizados e sob controle da administração, para resguardar a integridade documental. Isso se aplica a documentos com

\footnotetext{
${ }^{2}$ Sistema Informatizado de Gestão Arquivística de Documentos.
} 
alto grau de sigilo e segurança. Tratando-se do controle de acesso, faz-se referência à Norma ISO 15489, que, para Henriques (2002), "é a primeira norma ISO na área da documentação e informação que foca nuclearmente os processos que garantem um eficiente e sistemático controle da produção, conservação, utilização e eliminação da informação [...]".

A Norma ISO 15489 propõe a existência de controles de acesso apropriados, garantindo meio para o acesso. Os documentos de arquivo são divididos por categorias, de acordo com a gama de acesso em um determinado momento, e as pessoas devem ter permissão para acessálos. Nesse sentido, Castro, Castro e Gasparin (2007, p. 23) colocam que, além dos requisitos já identificados, essa Norma ainda contempla "sugestões e requisitos que os arquivistas podem utilizar: cooperação com outros profissionais da informação, boas práticas de gestão necessárias para a produção e preservação de documentos de arquivo, com qualidade".

\section{Metodologia}

A metodologia foi definida para atender aos objetivos de pesquisa que visam conhecer quais políticas de controle de acesso são desenvolvidas em instituições arquivísticas. Para isso, utilizaram-se como referencial teórico as Normalizações Arquivísticas e os Modelos de Requisitos. Isso foi definido tendo em vista que a Nobrade e o e-ARQ são publicações brasileiras, já o MoReq e a $\operatorname{ISAD}(G)$ serviram de subsídios para sua elaboração. Ao que se refere à Norma ISO 15489, ela foi escolhida por ter sido a primeira Norma ISO que visa a gestão de arquivos.

Os instrumentos escolhidos para a coleta de dados foram 0 questionário e a entrevista estruturada. O primeiro foi entregue a todas as pessoas envolvidas na gestão documental denominadas informalmente "técnicos de arquivo", o que não corresponde à definição dada na legislação ${ }^{3}$. O segundo foi aplicado à pessoa cujo conhecimento e envolvimento com o tratamento documental pudesse responder aos questionamentos a respeito do funcionamento do arquivo.

$\mathrm{Na}$ escolha do universo da pesquisa foi utilizado como critério a existência, na instituição, de no mínimo um arquivista em seu quadro de funcionários, já que foi proposto na presente investigação utilizar, como pressuposto, a adoção de Normalizações Arquivísticas e/ou Modelos de Requisitos para controle de acesso documental. As instituições escolhidas foram o APERS e o AHPAMV.

\section{Instituições}

Ao visitar as instituições arquivísticas a serem estudadas, foi possível, além de observar os aspectos arquitetônicos, conhecer um pouco

\footnotetext{
${ }^{3}$ Lei no․ 6.546, de 4 de julho de 1978.
} 
de sua trajetória, o seu acervo e outras características que, somadas, possibilitaram traçar resumidamente o histórico de cada uma.

\subsection{Arquivo Público do Estado do Rio Grande do Sul - APERS}

O Arquivo Público do Estado do Rio Grande do Sul é um departamento da Secretaria da Administração e dos Recursos Humanos. A sua estrutura é separada em duas divisões e uma seção: a divisão de Pesquisa e Projetos, a de Documentação, e a seção de Apoio Administrativo. O prédio I foi concluído em 1912 e sua arquitetura foi devidamente planejada para comportar a grande demanda documental. As estantes altas e as paredes espessas formam prateleiras de ferro revestido por cimento. O piso de ferro vazado, além de permitir que o ar circule, areja o local. A crescente demanda de documentos fez com que o prédio I fosse esgotando seu espaço físico. Como solução para o problema, em 1918 iniciou-se a construção do prédio II. Na execução da obra foram utilizadas as mesmas técnicas do primeiro. O prédio III é composto pela parte administrativa e técnica do arquivo, é baseado na estrutura arquitetônica dos dois primeiros, e sua conclusão se deu no ano de 1950.

O tombamento do prédio define a sua relevância histórica e cultural, tanto de acordo com sua estrutura arquitetônica quanto pela sua composição documental. Hoje, o Arquivo Público do Estado do Rio Grande do Sul possui um total de quarenta e quatro (44) funcionários efetivos. A sua importância para a sociedade se reflete na procura documental diária de aproximadamente cento e trinta (130) usuários, além de visitantes interessados em conhecer e apreciar esta instituição que possui 5.300 metros lineares de documentos.

\subsection{Arquivo Histórico de Porto Alegre Moysés Vellinho}

O Arquivo reúne, preserva e difunde documentos sobre a Cidade de Porto Alegre. Seu acervo está aberto a pesquisadores, estudantes e à comunidade em geral.

O prédio é composto por duas casas, ou seja, construções residenciais que já serviram como instituição de ensino, sofrendo restaurações em 1994. Neste ano o prédio foi entregue ao Arquivo Histórico, o qual possui sala de exposições e auditório, que podem ser utilizados pela comunidade. O nome do arquivo foi dado em homenagem ao historiador gaúcho Moysés Vellinho, a indicação foi da Câmara Municipal de Porto Alegre.

Muitas lacunas sobre a origem do Arquivo estão sendo desvendadas para a publicação da segunda edição do Guia do Arquivo, sendo que sua primeira edição foi publicada em 1997, sem a utilização de alguma normalização. Essa nova edição utilizará a Nobrade para a descrição do acervo. Os documentos pertencentes ao Arquivo datam do séc. XVIII e 
compõe-se também de jornais antigos, formando a hemeroteca. O seu acervo é especificamente sobre a cidade de Porto Alegre, direcionando-se a um pesquisador acadêmico. Além disso, realiza projetos que visam a consciência e a preservação do patrimônio documental.

O Arquivo Histórico de Porto Alegre Moysés Vellinho possui um total de sete (7) funcionários e quatro (4) estagiários que realizam atividades relacionadas com o acervo e com o atendimento ao público. A relevância do Arquivo Histórico para o município de Porto Alegre está no seu acervo, que abrange e acolhe a história e a vivência da cidade.

\section{Políticas de controle de acesso utilizadas no APERS e no AHPAMV}

O importante ao adotar medidas que corroborem a proteção das informações em uma instituição, seja ela pública ou privada, é saber que a não segurança do arquivo pode gerar a inconfiabilidade das informações que serão recebidas pelos usuários. As insituições devem estar cientes da relevância do controle de acesso e dos riscos que a falta dele causará, já que, ao monitorar o acesso aos documentos, pode-se garantir também a proteção dos bens materiais da instituição.

Em relação às políticas de controle do acesso, além de empregá-las, as instituições devem sentir-se capacitadas para controlá-las. Para Rossato (2001, p. 34), "as políticas de acesso aos documentos também constituem meios de difusão em arquivos, porque é possibilitando a consulta aos documentos que se promove o acesso".

O resultado da pesquisa esclareceu as indagações propostas, permitindo verificar medidas a serem aplicadas para disponibilizar a informação aos usuários e garantir o controle de acesso nas instituições. Com a coleta de dados, foi possível recolher um total de dezoito (18) questionários considerados válidos, abrangendo as duas instituições arquivísticas em estudo. Dados assim configurados: quatro (4) questionários que representam um percentual de $22,2 \%$ e que correspondem aos técnicos do Arquivo Histórico de Porto Alegre Moysés Vellinho; e quatorze (14) questionários que representam um percentual de $77,8 \%$ e que correspondem aos técnicos do Arquivo Público do Estado do Rio Grande do Sul, em consonância com os critérios metodológicos estabelecidos na pesquisa.

O primeiro grupo de perguntas se referia aos "dados pessoais e profissionais dos entrevistados", como forma de contextualizar os sujeitos pesquisados, definindo, assim, um perfil dos profissionais atuantes no APERS e no AHPAMV. No estudo foi possível identificar que 38,9\% pertencem ao sexo masculino e $61,1 \%$ ao sexo feminino. Da mesma forma, a faixa etária predominante entre eles foi entre 41 e 50 anos. Quanto ao tempo de serviço dos entrevistados, constatou-se que 44,4\% trabalham na instituição há mais de dez (10) anos, evidenciando uma longa trajetória profissional. Assim, foi possível constatar que o perfil do profissional das instituições em estudo, em sua maioria, corresponde ao 
sexo feminino, com uma estabilidade profissional comprovada pelo tempo de serviço, e a faixa etária entre 41 e 50 anos.

Para completar esse perfil, indagou-se qual a formação acadêmica dos mesmos, delimitando sua área de atuação, como também o nível, no caso de pós-graduação. Nessa perspectiva, Spitz (2007), de acordo com pesquisa realizada pelo IBGE (Instituto Brasileiro de Geografia e Estatística), afirma que no ano de 2006 houve um acréscimo no número de brasileiros que ingressaram no ensino superior. Esse fato foi evidenciado, na presente pesquisa, ao verificar-se que $83,3 \%$ dos profissionais que trabalham no APERS e no AHPAMV são graduados ou estão por concluir o curso. Dentre esses, 53,3\% correspondem aos graduados em Arquivologia, 33,3 \% em História e 6,7\% em Artes Plásticas/Arquitetura e Comunicação Social. Sendo relevante destacar que estas últimas correspondem a áreas afins à Arquivologia, ou seja, estes profissionais completam as atividades de gestão documental que são desenvolvidas nas instituições. O profissional formado em arquitetura colabora para o tratamento do acervo cartográfico e o profissional de comunicação social contribui no processo de difusão do acervo.

A interdisciplinaridade da História com a Arquivologia, por exemplo, é mencionada por Richter (2004), ao afirmar que o desenvolvimento de uma pesquisa histórica fundamenta-se em documentos, sendo que esses refletem as ações vividas por pessoas ao longo do tempo. Nessa mesma linha de pensamento, Erthal (2002, p. 10) comenta que o arquivista, como profissional da informação, deve trabalhar "de forma a dinamizar sua teoria nas incontáveis possibilidades de integração interdisciplinar para contribuir com o surgimento de novos possíveis produtos numa perspectiva transdisciplinar".

Assim também pensam Rousseau e Couture (1994, p. 262), ao afirmarem que as instituições necessitam de arquivistas "completos", ou seja, profissionais que saibam lidar com os mais diversificados suportes documentais. Em relação à importância da atualização profissional, Lopes (2000) observa, com razão, que o profissional arquivista deve tornar-se um produtor de conhecimentos, especializando-se e buscando aprimorar seus conhecimentos profissionais. Quanto a isto, as duas instituições relataram que os funcionários possuem horários flexíveis para a participação em eventos e em demais atividades que contribuam para a sua atualização profissional. Pode-se verificar, também, que menos da metade dos entrevistados possui curso de pós-graduação, ou seja, apenas $24,6 \%$ estão cursando ou já concluíram um curso de pós-graduação em nível de especialização. Este índice, encontrado através da pesquisa, demonstra que a maioria dos profissionais formados em cursos de graduação não realiza cursos de pós-graduação como forma de atualização e aprimoramento profissional.

O segundo grupo de perguntas se referia ao "controle de acesso", para verificar quais seriam as definições dos técnicos de arquivo sobre o assunto. Como é possível constatar, os profissionais que atuam no APERS e no AHPAMV reconhecem que o controle de acesso é feito através de 
regras utilizadas pelas instituições, sejam elas públicas ou privadas, para monitorar o acesso aos documentos e definir quem pode consultá-los. Ainda referindo-se ao conceito de controle de acesso, segundo os entrevistados ele pode conter as inúmeras ações desempenhadas por uma instituição, visando a segurança do seu patrimônio, seja com a utilização de alarmes, câmeras de segurança ou até com medidas de restrições ao manuseio da massa documental.

A definição das ações de controle de acesso, para os técnicos de arquivo, está em conformidade com 0 Instituto dos Arquivos Nacionais/Torre do Tombo (2002), ao afirmar que controle de acesso são medidas desenvolvidas pelas instituições, visando monitorar quem pode acessar os documentos e em que circunstâncias isso é possível. O Fórum do Patrimônio Documental (2006, p.6) considera ainda que "a instituição deve proceder ao registro de cada acervo adquirido, que pode ser um número de registro, de protocolo, tombo, ou código provisório".

O acesso aos registros dos documentos no e-ARQ diz respeito a requisitos que podem ser obrigatórios ou adicionais, referentes à identificação e autenticação de usuários, ou seja, aborda medidas de controle de acesso para adoção de um SIGAD. Ao referenciar os requisitos presentes nesse modelo, a Câmara Técnica de Documentos Eletrônicos (2006) define que um SIGAD deve manter características para acesso dos usuários, seguindo uma política de segurança, necessitando ao menos de cadastro do usuário e autorização de acesso ou credencial de autenticação (usado para sistemas informatizados ou não). Sendo assim, os usuários, mesmo em sistemas eletrônicos, podem ter acesso às informações mediante autorização.

A resposta dos profissionais entrevistados assemelha-se com a Normalização do ponto de vista das medidas de segurança. No APERS e no AHPAMV, da mesma forma, eles realizam o registro de seu acervo, onde o acesso é permitido tanto aos funcionários quanto aos usuários. Observou-se que esses registros, na opinião dos técnicos de arquivo, referem-se aos instrumentos de pesquisa, cuja função é facilitar o acesso aos documentos. A maioria dos entrevistados, perfazendo 57,1\%, afirmou que a instituição controla seu acervo através deste número de registro. Esse procedimento, em consonância com as Normalizações Arquivísticas e os Modelos de Requisitos, serve para verificar a movimentação do acervo documental e identificar a localização dos documentos.

Na análise de Beyea et al. (2007, p. 32), "os arquivistas [...] devem, nos processos que seguem e nas metodologias que aplicam, assegurar-se de que os documentos [...] sejam, ao longo do tempo, mantidos em seus contextos, complexos, originais e confiáveis." O uso das Normalizações assegura a qualidade destes processos, para que os documentos cumpram seu fim, permanecendo acessíveis o maior tempo possível.

Com o percentual de $87,5 \%$, a maioria dos entrevistados afirmou que utilizava as Normalizações Arquivísticas nas instituições. Estas respostas basearam-se em normas de descrição do acervo, que facilitam o acesso aos documentos, já que as instituições não seguem determinações 
teóricas para as ações de controle de acesso, segundo os entrevistados. Dessa forma, as instituições aplicam normas arquivísticas para a elaboração de instrumentos de pesquisa apenas porque corrobora o acesso tanto para os funcionários quanto para os usuários. Nessa perspectiva, Bellotto (2004, p.179) ressalta que "como os depósitos de arquivos, obviamente, nunca são de livre acesso, seu potencial de informações só chega ao usuário via instrumento de pesquisa".

Pode-se verificar que a Norma mais citada pelos entrevistados, nas duas instituições, foi a $\operatorname{ISAD}(\mathrm{G})$, pois é utilizada como padrão para a descrição do acervo documental. Ainda foram citadas a ISAAR(CPF), que serve para a descrição de documentos pessoais, abordando pequena parte do acervo do AHPAMV, e a Nobrade, que se encontra em processo de adaptação para posterior aplicação. Mesmo não sendo citados pelos entrevistados, o MoReq, o e-ARQ e a ISO 15489 possuem uma abordagem teórica ampla e completa no que tange ao controle de acesso. Em relação ao uso das Normalizações Arquivísticas, pode-se concluir, ainda, que a Norma $\operatorname{ISAD}(\mathrm{G})$ é a adotada nas instituições em estudo, já que a descrição do acervo facilita o acesso aos documentos por meio dos instrumentos de pesquisa.

A Norma brasileira de descrição, a Nobrade, por sua vez será gradativamente implementada nas instituições, segundo determinação do Conarq (Conselho Nacional de Arquivos). Da mesma forma, o MoReq, o eARQ e a ISO 15489 dificilmente são aplicados em instituições arquivísticas brasileiras. Eles também não são utilizados no APERS e no AHPAMV, mas, mesmo assim, o referencial teórico desses modelos de requisitos assemelha-se às ações praticadas para o controle de acesso em ambas as instituições.

Conforme Schellenberg (2006, p. 159), "no trabalho com seu material o arquivista visa a um duplo objetivo: preservá-los e torná-los disponíveis para ser usado". Nesse caso, os instrumentos de pesquisa executam esta função à medida que facilitam a procura documental. Os instrumentos de pesquisa em instituições como o APERS e o AHPAMV, que contam com profissionais da área arquivística, são importantes, e sua elaboração contribui para facilitar o acesso documental.

De tal modo, Bellotto (2004) afirma que a elaboração dos instrumentos de pesquisa deve iniciar do mais amplo para o menos amplo. O mais amplo dos instrumentos de pesquisa, nesse caso, é o guia de fundos, por permitir uma visão geral do acervo. Somente após a sua criação podem ser feitos o inventário, o catálogo e o índice, já que são mais específicos. Após análise, foi possível averiguar que as instituições arquivísticas pesquisadas possuem guia, inventário, catálogo e índice, mesmo que não abordem todo o acervo, mas são elaborados no intuito de conhecer os documentos e facilitar o acesso a eles.

As políticas atualmente adotadas nas instituições para controlar o acesso, tanto do APERS quanto do AHPAMV, são suficientes para garantir a segurança das informações, já que, segundo os entrevistados, não há registros de problemas maiores como roubo ou perda de informação. 
Ainda assim, na opinião dos técnicos de arquivo, é interessante que seja instalado um sistema de segurança patrimonial para evitar possíveis roubos e haver maior controle na movimentação do acervo. Também opinam na necessidade de uma cerca elétrica em torno do arquivo e da presença integral de um vigilante, o que melhoraria o controle de acesso das pessoas e conseqüentemente o controle documental. A Segurança da Informação consiste em garantir sigilo, integridade e acesso às informações, e, assim, uma instituição deve adotar cuidados para que a informação não seja adulterada ou perdida e permaneça sempre disponível para acesso dos usuários autorizados (AGÊNCIA ESTADUAL DE TECNOLOGIA DA INFORMAÇÃO, 2008).

Uma instituição, para se defender de possíveis ameaças que comprometam a segurança das informações, deve, além de criar políticas de segurança institucional, verificar quem possui acesso às informações sensíveis, ou seja, informações de acesso restrito e, além disso, proteger documentos que estejam em sistemas eletrônicos. Para salvaguardar estas informações é necessário, ainda, o uso de Normalização para a segurança das informações. A segurança é um processo e "deve ser tratada como um processo de gestão participativa, envolvendo todos os servidores" (CUNHA, 2009, p. 101).

Uma das preocupações, ao se estudar o controle de acesso e, principalmente, quando o referencial teórico são as Normalizações Arquivísticas, é a observância da legislação em vigor, quando se refere à documentação, principalmente em instituições públicas. O Conselho Nacional de Arquivos (2008, p. 44), no Decreto no 4.553, de 27 de dezembro de 2002, Art. 20, afirma que:

São considerados originariamente sigilosos, e serão como tal classificados, dados ou informações cujo conhecimento irrestrito ou divulgação possa acarretar qualquer risco à segurança da sociedade e do Estado, bem como aqueles necessários ao resguardo da inviolabilidade da intimidade da vida privada, da honra e da imagem das pessoas.

Para monitorar a movimentação de pessoas, as instituições adotam, ainda, regras internas que controlam o acesso aos documentos. Essas regras definem-se como condições de acesso impostas de acordo com as atividades, funções e necessidades de cada instituição. São regras como restrição de acesso ao espaço de guarda do acervo, apenas a funcionários. Podem ser também regras de conduta do usuário/pesquisador visando orientá-lo sobre as mesmas, para que a consulta ao documento seja segura e o manuseio não danifique o acervo documental, sob guarda da instituição.

A supervisão e o planejamento das permissões do usuário e das responsabilidades de trabalho representam um processo realizado em todos os sistemas da gerência de documentos do arquivo, independentemente do seu formato (INTERNATIONAL ORGANIZATION FOR STANDARDIZATION - ISO, 2001, tradução nossa). As questões técnicas de 
controle do acervo e de acesso aos documentos devem ser planejadas, objetivando disponibilizar as informações aos usuários, sem que ocorram perdas e extravios de documentos. Neste sentido:

A instituição deve registrar cada consulta de forma correta e objetiva, e estes registros devem ser guardados em local seguro e por um longo prazo, para que possam estar disponíveis e rapidamente recuperáveis a qualquer instante. Esta atitude permite que quaisquer perdas, danos ou roubos possam ser detectados, e rapidamente identificado quem utilizou o acervo e quando (FORÚM DO PATRIMÔNIO DOCUMENTAL, 2006, p. 6)

O controle de acesso utilizado nas instituições impõe aos usuários acesso restrito, somente à sala de pesquisa. Porém, alguns procedimentos diferem-se nos dois arquivos estudados. As cópias dos documentos nas duas instituições podem ser feitas com o uso de câmera, mas sem utilização de flash, pois o mesmo pode acelerar o processo de deterioração dos documentos.

No APERS, os usuários possuem acesso restrito somente à sala de pesquisa, todavia eles assinam um livro de registro com hora de entrada e saída, e só podem entrar na sala com uma folha de papel e lápis, deixando as bolsas no armário. Os pesquisadores/usuários também assinam um livro (na recepção) com dados para possível localização, contendo nome, endereço, telefone, número do CPF e Carteira de Identidade. A utilização de uma ficha de cadastro informatizada com os dados do pesquisador fica armazenada para cadastrá-lo, sendo que, cada vez que o pesquisador/usuário for pesquisar no arquivo, precisa assinar o livro com a data, hora de entrada e saída e o tema pesquisado. Esses procedimentos servem para assegurar a integridade das informações, evitando perdas e extravios de documentos.

Ao referir-se a conjuntos documentais de acesso restrito, deve-se ter cuidado para cumprir as determinações legais. Os entrevistados do APERS ainda afirmaram que existem dois conjuntos documentais de acesso restrito, conforme legislação. O primeiro refere-se aos documentos pertencentes ao Hospital Psiquiátrico São Pedro, onde só têm acesso as pessoas que passarem pela comissão de Ética Médica do hospital. O segundo pertence ao acervo do Poder Judiciário, onde somente é concedido acesso por meio de procuração e diretamente pela parte interessada.

A documentação do APERS, como relatado pelos entrevistados, está sendo gradativamente digitalizada há dois anos, seguindo a Norma $\operatorname{ISAD}(G)$, pois está sendo elaborando um grande índice, sendo que os documentos já digitados (indexados) encontram-se disponíveis para acesso no portal do arquivo.

O procedimento realizado no AHPAMV também evita o acesso dos usuários à sala do arquivo. O pesquisador chega ao arquivo, recebe uma 
ficha de cadastro e assina um livro contendo dados como nome, data e tema da pesquisa. Nesse mesmo instrumento é controlado o total anual de documentos movimentados. Dessa forma, para controlar o acervo utilizam-se dois instrumentos, o livro de controle e a ficha de cadastro. Quanto a documentos de acesso restrito, os entrevistados do AHPAMV afirmaram que a instituição não possui documentos com restrição de acesso, consoante à legislação, porém limitam o manuseio de documentos em estado avançado de degradação, para preservá-lo. Nessa perspectiva, Costa (2003, p. 6) relata que "os problemas de manuseio não se limitam apenas no momento em que os documentos estão nas mãos do usuário. Deve ser analisado todo o percurso, de ida e volta, entre a estante, a sala de consultas e de reprodução". Assim, o tratamento documental deve ser visto como um todo, reforçando-se, ainda mais, os cuidados quando se trata de documentos antigos ou em estado de conservação precários. Nesse caso é recomendado diminuir o manuseio. Além de empregar cuidados com o manuseio, restrições de acesso ou outras medidas de controle, as instituições estudadas realizam reuniões com os funcionários, objetivando dar treinamento, avaliar a semana de trabalho e resolver possíveis problemas.

Para Rossato (2001), as instituições devem satisfazer as necessidades dos usuários e para isso é importante conhecer a avaliação deles sobre os serviços oferecidos. Dessa forma, mesmo sendo relevante reconhecer a opinião dos usuários, o APERS e o AHPAMV ressaltaram estar abertos a sugestões e críticas, embora não possuam instrumento formalizado para executá-las. Mesmo assim, se os usuários julgarem necessário, podem deixar sua opinião através do correio eletrônico (e-mail institucional). Este procedimento evidencia que mesmo não possuindo um instrumento para avaliação dos serviços prestados, as instituições verificam a importância da opinião dada pelo usuário, pois, a partir dela, poderão aprimorar estes serviços a fim de servi-lo.

O MoReq e o e-Arq são modelos de requisitos mais específicos para o tratamento de documentos eletrônicos/digitais. As instituições em estudo não utilizam sistemas eletrônicos para a gestão de documentos e, como visto anteriormente, não adotam estas normas no acervo. Entretanto, empregam recursos informatizados apenas para facilitar 0 acesso documental, por meio dos instrumentos de pesquisa. O mais comum, em instituições arquivísticas que não dispõem de recursos financeiros e tecnológicos para a implementação de sistemas de gestão eletrônica, é o uso de bancos de dados para a elaboração de instrumentos de pesquisa em meio eletrônico/digital que, sendo impressos, ficam disponíveis à consulta, facilitando o acesso e o desenvolvimento das atividades institucionais.

\section{Conclusões}

O controle de acesso como foco do estudo possibilitou verificar que a maior parte dos técnicos de arquivo possui graduação em Arquivologia, o 
que afirma seu conhecimento sobre as Normalizações Arquivísticas. Os entrevistados, em sua maioria, determinaram que o controle de acesso é feito por regras e normas que devem ser seguidas pelos usuários do arquivo, como um critério de segurança para o acervo. A relevância da adoção de políticas para garantir o controle e segurança das informações foi generalizada entre os técnicos de arquivo.

Desta maneira, além da proporcionar medidas de segurança para o acervo, as instituições procuram, através dos instrumentos de pesquisa, difundir o arquivo e facilitar o acesso a ele. Com base no estudo realizado no APERS e no AHPAMV, os instrumentos de pesquisa mais citados foram guia, catálogo e índice. Segundo as respostas dos questionários, de acordo com as entrevistas realizadas nas instituições, foi possível confirmar que também possuem inventário.

As duas instituições, mesmo não trabalhando com documentos eletrônicos, verificam a necessidade da informatização do acervo. Elas possuem apenas instrumentos de pesquisa em base de dados onde 0 acesso ao sistema restringe-se aos funcionários. Esse procedimento é uma medida de segurança para preservar as informações institucionais, evitando que sejam alteradas ou excluídas. À medida que os instrumentos podem ser acessados, poderão também ser impressos, ficando disponíveis para consulta dos usuários.

A elaboração de instrumentos de pesquisa é resultante do uso das normas de descrição arquivísticas que, para Beyea et al. (2007), são as mais conhecidas e aplicadas pelos profissionais de arquivo. As políticas adotadas para o controle de acesso nas instituições estão em consonância, principalmente, com o referencial teórico dos modelos de requisitos MoReq e e-ARQ.

Em primeiro lugar, a norma mais citada foi a $\operatorname{ISAD}(G)$, pois o processo de descrição documental, em ambas as instituições, foram baseadas nesta normalização. Entretanto, um dos arquivos iniciou a aplicação da Nobrade para cumprir com a determinação do Conselho Nacional de Arquivos (Conarq), o qual recomenda a utilização de normas nacionais. Mesmo não sendo citados a Norma ISO 15489 e os Modelos eARQ e MoReq, alguns procedimentos adotados pelas instituições são semelhantes às regulamentações presentes neles.

Em segundo lugar, os Modelos e-Arq e MoReq, mesmo visando a gestão de sistemas informatizados, possuem relação com as regras adotadas nas instituições. Segundo as duas normas, o acesso deve ser permitido apenas a pessoas autorizadas. Com base nas respostas dos entrevistados, constatou-se que as instituições utilizam um número para registro do acervo, e que apenas os funcionários têm permissão de acesso ao sistema, prevenindo assim a alteração ou a perda de informação. 0 que fica disponível aos usuários são os instrumentos de pesquisa. As normas visam a que o administrador, no caso o diretor da instituição, defina quem pode ou não ter acesso aos registros e, segundo afirmações, todos os funcionários possuem acesso livre ao acervo. 
Outro ponto que confere com as normalizações é o controle de usuários e visitantes, ou seja, quanto à entrada e saída nas dependências do arquivo. Os técnicos de arquivo afirmaram que o usuário não tem acesso à sala do arquivo. Assim, o procedimento realizado para controle é o uso de um livro de registro e uma ficha de cadastro. No APERS, este cadastro é informatizado. Nesse caso, a Câmara Técnica de Documentos Eletrônicos (2006, p. 73) sugere a utilização de cópias de segurança, que "têm por objetivo prevenir a perda de informações, e garantir a disponibilidade do sistema".

As políticas de controle de acesso adotadas, na opinião dos entrevistados, garantem a segurança das informações institucionais, pois, segundo eles, não ocorreram problemas como perda ou furto de documentos. Mesmo assim, eles colocam a necessidade de maior controle do acervo, através do reforço da segurança e o aumento do número de funcionários. Jardim (1995, p. 8) salienta que as instituições devem revisar suas medidas de segurança, pois "a ausência de padrões [...] somada às limitações de recursos humanos, materiais e tecnológicos, resultam em deficiências no processamento técnico".

Alcançados os objetivos propostos na pesquisa, recomenda-se que as instituições cobrem das autoridades governamentais apoio e incentivo para a implantação de sistemas informatizados de gestão documental, a fim de facilitar tanto o acesso dos usuários quanto o da própria administração. No intuito de reforçar o controle sobre a movimentação de pessoas nas instituições, foi sugerida, pelos técnicos, a utilização de um circuito interno e externo de câmeras de segurança, visando à identificação de possíveis furtos de materiais documentais ou patrimoniais.

Deve-se ressaltar ainda que, ao investigar as políticas de controle de acesso aplicadas atualmente nas instituições arquivísticas, pode-se aprimorar e adequar esses métodos utilizados, garantindo, assim, maior segurança das informações institucionais. As políticas de controle de acesso, segundo os técnicos de arquivo do APERS e do AHPAMV, são suficientes para a segurança do acervo. No entanto, o que os usuários pensam disso? Este questionamento pode ser abordado como continuação dessa mesma pesquisa ou dar início a uma nova investigação, complementando e suprimindo a carência de material bibliográfico sobre o tema proposto.

\section{Referências}

AGÊNCIA ESTADUAL DE TECNOLOGIA DA INFORMAÇÃO. Política de segurança da informação da ATI - PSI/ATI. 2008. Agência Estadual de Tecnologia da Informação. Disponível em: $<$ www2.ati.pe.gov.br/.../get file?folderld=1650\&name=Microsoft Word PolíticaSegurançalnformação.pdf >. Acesso em: 28 maio 2008.

BELLOTTO, H. L. Arquivos Permanentes: tratamento documental. Rio de Janeiro: FGV, 2004. 
BEYEA, M. et al. A Favor de Normas para a Prática Arquivística. Acervo. Rio de Janeiro, v. 20 n. 1-2, p. 31-38, jan/dez 2007.

BRASIL. Constituição da República Federativa do Brasil de 1988. Brasília, 5 de outubro de 1988. Disponível em: <http://www.planalto.gov.br/ccivil 03/constituicao/constitui\%C3\%A7ao.htm>.

Acesso em: 13 ago. 2009.

. Conselho Nacional de Arquivos. Decreto n. 3.505, de 13 de junho de 2000. Institui a Política de Segurança da Informação nos órgãos e entidades da Administração Pública Federal. Diário Oficial da União, 14 de junho de 2000. p. 2.

- Conselho Nacional de Arquivos. Decreto n. 4.553, de 27 de dezembro de 2002, Dispõe sobre a salvaguarda de dados, informações, documentos e materiais sigilosos de interesse da segurança da sociedade e do Estado, no âmbito da Administração Pública Federal, e dá outras providências. Diário Oficial da União, 30 de dezembro de 2002. p. 6.

. Conselho Nacional de Arquivos. Lei n. 9.507, de 12 de novembro de 1997. Regula o direito de acesso a informações e disciplina o rito processual do habeas data. Ministério da Justiça. Diário Oficial da União, 13 de novembro de 1997. p. 26025.

. Conselho Nacional de Arquivos. Resolução n. 20, de 16 de julho de 2004. Dispõe sobre a inserção dos documentos digitais em programas de gestão arquivística de documentos dos órgãos e entidades integrantes do Sistema Nacional de Arquivos. Aprovado pela Portaria n. 5, da Casa Civil da Presidência da República, de 7 de fevereiro de 2002, de conformidade com a deliberação do Plenário, em sua $34^{a}$ reunião ordinária, realizada em 6 de julho de 2004.

CÂMARA TÉCNICA DE DOCUMENTOS ELETRÔNICOS. Modelo de Requisitos para Sistemas Informatizados de Gestão Arquivística de Documentos: eARQ. Rio de Janeito: Conarq, 2006. Disponível em: <http://www.conarq.arquivonacional.gov.br/Media/publicacoes/earqbrasilv1.pdf >.

Acesso em: 09 out. 2007.

CARDOSO, J. C.; LUZ, A. R. Os arquivos e os sistemas de gestão da Qualidade. Arquivística.net, Rio de Janeiro, v.1, n.1, p.51-64, jan./jun. 2005.

$<$ www.arquivistica.net/ojs/include/getdoc. $p h p$ ? id $=51 \&$ article $=6 \&$ mode $=$ pdf $>$.

Acesso em: 18 nov. 2006.

CASTRO, A. M.; CASTRO, A. M.; GASPARIN, D. M. C. Arquivos: físicos e digitais. Brasília: Thesaurus, 2007.

CONSELHO NACIONAL DE ARQUIVOS. NOBRADE: Norma brasileira de descrição arquivística. Rio de Janeiro: CONARQ, 2006. Disponível em: $<$ www.portalan.arquivonacional.gov.br/Media/nobrade.pdf $>$. Acesso em: 25 fev. 2007. 
- ISAAR (CPF): norma internacional de registro de autoridade arquivística para entidades coletivas, pessoas e famílias. Rio de Janeiro: Arquivo Nacional, 2004. Disponível em: <http://www.conarq.arquivonacional.gov.br/Media/publicacoes/isaar cpf.pdf > Acesso em: 26 maio 2008.

- $\operatorname{ISAD}(G)$ : Norma geral internacional de descrição arquivística. Adotada pelo Comitê de Normas de Descrição, Estocolmo, Suécia, 19-22 de setembro de 1999, versão final aprovada pelo CIA. Rio de Janeiro: Arquivo Nacional, 2 ed. 2000. Disponível em:

<http://www.conarq.arquivonacional.gov.br/Media/publicacoes/isad g 2001.pdf>. Acesso em: 21 nov. 2007.

Disponível

Legislação Arquivística Brasileira. Rio de Janeiro: CONARQ, 2008. <http://www.conarq.arquivonacional.gov.br/Media/legarquivosfevereiro2008.pdf > . Acesso em: 29 abr. 2008.

COSTA, M. F. Noções básicas de conservação preventiva de documentos. Rio de Janeiro: Centro de Informação Científica e Tecnológica; Biblioteca de Manguinhos; Laboratório de Conservação Preventiva de Documentos, 2003. Disponível em: <http://www.bibmanguinhos.cict.fiocruz.br/normasconservacao.pdf $>$. Acesso em: 27 maio 2008.

CUNHA, M. R. Curso de Segurança da Informação. Porto Alegre: Associação dos Arquivistas do Estado do Rio Grande do Sul, 14 e 15 de maio de 2009. 308 slides. [Apresentação em Power Point].

ERTHAR, D. Representação e registro: o papel do profissional arquivista na preservação do patrimônio documental. [S.I. : s.n.], 2002. Disponível em: <www.asocarchi.cl/DOCS/60.PDF>. Acesso em: 15 maio 2008.

FÓRUM DO PATRIMÔNIO DOCUMENTAL. Grupo de trabalho de controle de acesso e circulação de acervo. Documento final. Rio de janeiro, julho 2006. Disponível em: <www.aab.org.br/download/GT acervo25jul.pdf>. Acesso em: 1 abr. 2008.

HENRIQUES, C. ISO 15489-1 e ISO/TR 15489-2: uma Norma para gestão de arquivos. Lisboa: Instituto dos Arquivos Nacionais/Torre do Tombo, 2002. Disponível

em: <www.dotecome.com/infoimagem/infoimagem/info38/38art3.htm - 15k >. Acesso em: 21 abr. 2008.

HEREDIA HERRERA, A. La Norma ISAD(G) "Análisis Crítico": Norma Internacional para la descripción archivística. 2008. Disponível em: <http://infolac.ucol.mx/documentos/isad.pdf>. Acesso em 19 abr. 2008.

INSTITUTO DOS ARQUIVOS NACIONAIS/TORRE DO TOMBO. Caderno de Recomendações para gestão de documentos de arquivo electrónicos: Modelo de requisitos para gestão de arquivos electrónicos - MoReq. 
Lisboa: IAN/Torre do Tombo, 2002. Disponível em: < http://www.iantt.pt>. Acesso em: 21 nov. 2007.

JARDIM, J. M. A invenção da memória nos arquivos públicos. Ciência da Informação, $\quad$. 25, n. 2, 1995. Disponível em: $<$ www.ibict.br/cionline/include/getdoc.php?id=818\&article $=480 \&$ mode $=p d f>$. Acesso em: 11 nov. 2007.

LEÃO, F. C. A representação da informação arquivística permanente: a normalização descritiva e a ISAD (G). São Paulo: [s.n.], 2006. Disponível em:

$<$ poseca.incubadora.fapesp.br/portal/informacao/outrosccom/dados/2006/titulo/-53k>. Acesso em: 9 abr. 2008.

LOPES, L. C. A nova arquivística na modernização administrativa. Rio de Janeiro: Papéis e Sistemas Assessoria Ltda, 2000.

LUZ, A. R. A. V. Normas Arquivísticas e Padrões de descrição de metadados aplicados à preservação do patrimônio arquivístico digital. $2008 . \quad$ Disponível em: $<$ http://dici.ibict.br/archive/00000303/01/Normas Arquiv\%C3\%ADsitca e

Padr\%C3\%B5es de Descri\%C3\%A7\%C3\%A30 de Metadados.pdf>. Acesso em: 11 abr. 2008.

INTERNATIONAL ORGANIZATION FOR STANDARDIZATION (ISO). ISO 15489-1: International Standard - Information and documentation - Records management Part 1: General. 2001. 26p.

RICHTER, E. I. S. Introdução à Arquivologia. Santa Maria: FACOS-UFSM, 2004.

ROSSATO, C. A. O arquivo público do Estado do Rio Grande do Sul na percepção de usuários: um ambiente a ser descoberto. Dissertação (Mestrado) - Universidade Federal de Santa Catarina, Florianópolis, 2001.

ROUSSEAU, J.; COUTURE, C. Os fundamentos da disciplina arquivística. Lisboa: Dom Quixote, 1998.

SARAMAGO. M. L. Metadados para preservação digital e aplicação do modelo OAIS. Lisboa: Biblioteca do Departamento de Biologia Animal da Faculdade de Ciências da Universidade de Lisboa, 2004. Disponível em: <http://badinfo.apbad.pt/congresso8/comm2.pdf>. Acesso em: 18 jun. 2008.

SCHELLENBERG, T. R. Arquivos Modernos: princípios e técnicas. Rio de Janeiro: FGV, 2006.

SPITZ, C. Número de estudantes no nível superior cresce 13,2\%, diz IBGE. Folha Online. Rio de Janeiro, 2007. Disponível em: <www1.folha.uol.com.br/folha/educacao/ult305u328297.shtml-29k>. Acesso em: 18 jun. 2008. 